This is an electronic reprint of the original article. This reprint may differ from the original in pagination and typographic detail.

Author(s): Tapiola, Titta; Paloviita, Ari

Title: Building resilient food supply chains for the future

Year: $\quad 2015$

Version:

Please cite the original version:

Tapiola, T., \& Paloviita, A. (2015). Building resilient food supply chains for the future. In A. Paloviita, \& M. Järvelä (Eds.), Climate Change Adaptation and Food Supply Chain Management (pp. 30-42). Routledge. Routledge Advances in Climate Change Research. https://doi.org/10.4324/9781315757728

All material supplied via JYX is protected by copyright and other intellectual property rights, and duplication or sale of all or part of any of the repository collections is not permitted, except that material may be duplicated by you for your research use or educational purposes in electronic or print form. You must obtain permission for any other use. Electronic or print copies may not be offered, whether for sale or otherwise to anyone who is not an authorised user. 


\title{
Chapter 3 - Building Resilient Food Supply Chains for the Future
}

\author{
Titta Tapiola ${ }^{1} \&$ Ari Paloviita ${ }^{2}$
}

\author{
${ }^{1}$ Natural Resources Institute Finland, FI-31600 Jokioinen, Finland; titta.tapiola@luke.fi \\ ${ }^{2}$ University of Jyväskylä, Department of Social Sciences and Philosophy, P.O. Box 35, 40014 \\ University of Jyväskylä, Finland; ari.paloviita@jyu.fi
}

\section{Introduction}

Modern food systems consist of the networks of activities and infrastructure needed to feed a certain population. The key activities of food supply chains involve input industries, primary production, food processing and manufacturing, distribution, retail, food services and consumption. Essential inputs into the food system, such as energy, fertilizers, pesticides and machinery, are vital and often imported into Finland as they are mainly produced from or by using fossil fuels. Modern food systems are heavily dependent on these inputs to be able to function properly. It could be said that modern food systems run on oil (Woods et al. 2010, 2991-2992; Bomford 2010, 121-122).

All the activities above have social, cultural, economic, environmental and political aspects, including the governing and research institutions and organisations. According to Ericksen $(2008 \mathrm{~b}, 16)$ the main objective of food systems is food security. In Europe, food security is associated for example with improved understanding of the sources of food waste, which is significantly produced at all levels of the food supply chain (Kumar et al. 2013). Food security can also be viewed as part of the corporate social responsibility strategies of the food industry and retailing companies (Manning 2013). Hence, there is a close interdependence between food security and the sustainable food system.

Modern food systems face global drivers, for example, climate change, a growing population, a growing elderly population, urbanisation, changes in diets, and economic crises that influence food prices and so on (Misselhorn et al. 2012, 8). In addition, possible peak oil costs, structural changes in food systems, such as homogenisation and concentration, plus diminishing natural resources, will also entail risks and opportunities for future food systems and food security (Ericksen 2008b, 20; Ericksen 2008a, 235, Rockström et al. 2009, 473; Woods et al. 2010, 2991-2992, 2998). Food is also interlinked 
with water and energy (fossil fuels) (Stigson 2013, 2). Water scarcities, on the other hand, and flooding, on the other, are estimated to increase as the climate change proceeds and both have impacts on food security (Wheeler \& von Braun 2013).

When considering unlikely phenomena and having little knowledge about their measures, managing food systems for resilience and building resilience for food security offer a useful approach. It is possible to be prepared or at least plan for phenomena that we are aware and have some well-informed scenarios about climate change adaptation and other issues. Nevertheless, there will doubtless be shocks and stresses that are not possible to foresee or forecast. Casti et al. $(2011,4-5)$ list five reasons for the emergence of unexpected events: 1) increasing complexity and a limited human ability to understand and control the behaviour of complexities; 2) flat-world instability i.e. the interdependencies of individual actions on a global level; 3) paradigm shifts representing major large scale discontinuities, e.g. technological innovations; 4) unresolved global drivers reaching their tipping point and the subsequent consequences; 5) some current characteristics of modern societies, such as the appreciation of individualism, specialisation and short-sightedness, can work against long-term thinking.

Food systems are vulnerable to events caused by complexity, global interdependency, paradigm shifts and unresolved global drivers, such as climate change and even the fundamental characteristics of our society. Concern about the resilience of modern food systems and food supply chains raises many questions about their present and future resilience. Therefore this work looks for answers to two questions: How do food system experts perceive the current resilience of the Finnish food system? How do the same experts foresee that current resilience to have changed by 2050 ?

It is somewhat worrying how little time is spent thinking about our potential futures with regard to the long-term, or for preparing ourselves for how food systems might be different in the future. The purpose of the theories used in this work is not to explain what might be or will be. It is not possible to predict futures, but it might be possible to open new windows to the endless opportunities and threats, thus influencing decisions taken today and leading our future development in more preferable directions. This chapter aims to raise awareness of resilience thinking and inspire key actors in the food supply chain to take action towards securing a preferable future for our common food system.

\section{General resilience and resilience assessment}


Resilience is a system level concept and unlike sustainability it is not fundamentally normative, i.e. it does not include specific choices about performance measure. Usually there is need to define "resilience of what to what" (resilience of a certain system to a certain disturbance or event). When "resilience of what to what" has been defined, it is referred as a specified resilience, e.g. resilience of a certain food supply chain to climate change.

On the other hand general resilience refers to a broader set of system attributes, such as the amount of change a system can withstand, self-organising behaviour, connectedness, diversity, modularity and the capacity for learning (see Walker and Salt 2006, 121; 145-148, Carpenter et al. 2012). General resilience leaves external conditions more open for shocks, including unlikely events. Specified resilience, i.e. having more carefully defined system boundaries, is close to the concept of robustness (Anderies et al. 2013; Resilience Alliance 2007; Resilience Alliance 2010).

Food systems are complex examples of the socio-ecological system (SES). There have been many attempts to operationalise the measurement of the resilience of SESs, but only with some success, which is often connected to the systems having a well-defined spatial and temporal scale (Walker and Salt 2006). The measurement of resilience is difficult because it actually requires measuring the thresholds or boundaries between different regimes. That is why the resilience of a SES is not observable or directly measurable. However, Carpenter et al. (2005) list four approaches for developing indicators or surrogates: 1) aspects of the resilience of a SES are identified by using stakeholder assessment; 2) models - scenarios, computer simulations - are used to examine the potential thresholds; 3) historical profiling is used to compare similar SESs and regime shifts; 4) case study comparisons are used for examining similar SESs. Each approach has its own weaknesses and strengths, therefore a combination of them would secure more robust indicators. In connection with climate change, Engle et al. (2013) have constructed preliminary categories of a "hybrid" resilience framework with five groups of indicators: governance and security, natural resources, social systems, economic systems and infrastructure.

General resilience parameters are typically difficult to apply directly into practice, especially to complex systems such as food systems. However, one promising indicator framework is the behaviourbased indicator framework developed by Cabell and Oelofse (2012) for assessing the resilience of agriecosystems. According to our literature review, these indicators can be applied and used in the general resilience framework. We will use 13 indicators of this framework to explore the resilience of the 
Finnish food system. Although these indicators are originally developed for measuring the resilience of agri-ecosystems, their general resilience characteristics make most of them applicable to the overall food system. The indicators and their reference to general resilience parameters are described in the following:

1. "Socially self-organised" refers to the general parameters of self-organising behaviour, and the resulting innovation and experimentation (see Walker and Salt 2006, 121, 145-148). Meadows (2008, 79-80) defines self-organisation as a system's capability to make its own structure more complex.

2. "Ecologically self-regulated" refers to the general parameters of connectedness and feedbacks. The tightness of the feedbacks or responsiveness (connections) represents the speed of how quickly and strongly a change in one part of a system is felt in other parts of the system (Walker and Salt 2006, 121, 145-148). Carpenter et al. (2012) describe feedbacks as linkages in control and response variables. Davidson et al. (2013) list feedbacks as one of the critical resilience dimensions. Hence, an ecologically self-regulated indicator measures how ecological components self-regulate via stabilising feedback mechanisms that send information back to controlling elements.

3. "Appropriately connected" refers to the general parameters of connectedness and feedbacks, describing the quantity and quality of relationships between system elements.

4. "Functional and response diversity" refers to the general parameter of diversity, measuring the variety of ecosystem services and range of responses to the environmental change. Diversity highlights the number of different actors - people, species, business and food supplies - that form a system (Walker and Salt 2006, 121, 145-148).

5. "Optimally redundant" - a system that has optimally extra resources - refers to general parameters of modularity, independently functioning modules and backups. Modularity measures the separate components and links between the components of a system (Walker and Salt 2006, 121, 145-148). Carpenter et al. (2012) describe modularity as independent and similar systems or functions to secure functioning, even if one module fails. Hence, optimally redundant means critical components and relationships are duplicated to prevent failure. The amount of change a system can withstand while maintaining its main functions and structure associates with its reserves (for the regeneration of key components) and redundancy (Carpenter et al. 2012). Sheffi (2005) identifies increased redundancy, 
i.e. keeping an extra food inventory, maintaining low capacity utilisation and the multi-sourcing of food, as a way to develop supply chain resilience, although it has limited utility.

6. "Spatial and temporal heterogeneity" refers to the general parameter of diversity, measuring patchiness (degrees of heterogeneity) across a landscape and changes over time. Diversity may also mean a diversity of land use - the opposite of monocultures (Walker and Salt 2006, 121, 145-148). On the other hand, self-organisation produces heterogeneity and unpredictability, but requires freedom and some disorder to occur (Meadows 2008, 80).

7. "Exposed to disturbances" refers to the general parameters of "practising" self-organising behaviour and the capacity for learning, meaning that the system can be exposed to low-level events that cause disruptions without pushing beyond the critical threshold. According to Davidson et al. (2013), the likelihood of crossing critical thresholds is one of the critical resilience dimensions.

8. "Coupled with local natural capital" refers to the general parameters of modularity, self-organising and connectedness, meaning that the system functions mainly within a regionally available natural resource base and ecosystem services. According to Carpenter et al. (2012), nestedness is a concept that enables large scale challenges to be turned into more natural scale, such as the village or community level.

9. "Reflected and shared learning" refers to the general parameter of the capacity for learning, which emphasises how individuals and institutions learn from past and present experimentation to anticipate change and create desirable futures. According to Davidson et al. (2013), openness to resilience thinking is one of the critical resilience dimensions.

10. "Globally autonomous and locally interdependent" refers to the general parameters of modularity, self-organising and connectedness, in which the systems have relative autonomy from global control and hence more local cooperation.

11. "Honours legacy" refers to the general parameters of the capacity for learning and trust, meaning that the current configuration and future trajectories of a system are influenced by past conditions and experiences. Trust enables effective collaboration and is developed in repeated interactions (Carpenter et al. 2012). 
12. "Builds human capital" refers to the general parameters of the capacity for learning and trust, measuring the ability of a system to take advantage of and to build social relationships and memberships in social networks; leadership enables building and maintaining networks (Carpenter et al. 2012).

13. "Reasonably profitable" refers to the general parameter of the capacity for self-organising behaviour, measuring the ability of segments of society to make a livelihood from the work they do without relying too heavily for example on subsidies or secondary employment.

In the next sections, the resilience of the current Finnish food system and its resilience in the year 2050 is assessed by using the above mentioned framework of 13 resilience indicators. We argue that this type of coarse information can be useful in profiling the degree of resilience of different food supply chain subsystems and will help to provide a starting point for resilience management.

\section{Present resilience of the Finnish food system}

The method used was an electronic survey of 63 experts (individual respondents). The invited experts were from research organisations, the food industry, the retail and farmers' support organisation ProAgria. The behaviour-based indicator framework for assessing the resilience of agri-ecosystems was utilised when constructing the claims of the expert survey. It was also investigated whether, according to the experts' views, there are some types of farms (small, medium or large farms; organic, plant or livestock production farms), industries (small, medium or large businesses) or retail actors (local, national or international) that seem to be more resilient than others. The expert survey had four sections respondents could choose from: primary production, food industry, retail, and consumption. The respondent could also answer more than one section. There were 25-27 respondents (the variation is due to the fact that some respondents did not answer all the questions) in the section concerning primary production, 20-22 respondents in the food industry section, 13-14 respondents in the retail section and 36-37 respondents in the consumer attitudes and behaviour section. The scale used was the Likert scale (1-5). The Likert-scale data was complemented with written comments by the experts.

For each sub-system of the food supply chain system the most relevant set of indicators were selected, because primary production, the food industry, retailers and consumers operate in varying 
environments. Hence, only some of the indicators were applied to all sub-systems. As the indicator framework used was primarily made for assessing the general resilience of agri-ecosystems, the indicators were especially applicable to primary production, but many of them were also applicable to other sub-systems of the food system. The results (the means of the responses) are presented in Table 3.1 .

[Insert table 3.1. here]

Table 3.1 Present status of resilience of primary production, food industry and retail according to the expert survey. Primary production is divided into small (S), medium (M), large (L), organic (Org.), plant production (PP) and livestock (LF) farms. Food industry is divided into small (S), medium (M) and large (L) businesses. Retail sector is divided into local (Loc.), national (Nat.) and international (Int.) actors. Degree of resilience is illustrated as follows: low (white, mean of responses 0-2.6), medium (light gray, mean of responses 2.7-3.3) and high (dark gray, mean of responses 3.4-5).

Source: the authors

The present resilience of primary production was measured by ten indicators. In general, organic farms are perceived as the most resilient farm type by the experts. Indicator 8, coupled with local natural capital, represents the lowest degree of resilience in primary production. Farms are typically dependent on imported natural capital, such as oil, fertilizers and pesticides. The highest degree of resilience is shown by indicator 9, reflected and shared learning, which means that farmers are able and willing to share their learning and know-how and have the capability to develop their livelihoods and possibly originate new behaviours or structures if necessary. Some experts commented that farms have prepared for some rare but probable situations, such as power failure, but there were few opportunities to have or adopt redundancy (indicator 5) due to tight financial situations.

The present resilience of food industry was measured with 7 indicators. In the food industry, it appears that larger businesses seem to have a higher resilience than smaller businesses. Indicator 5, optimally redundant, represents the lowest degree of resilience in the food industry. The experts believe the food industry operates very efficiently but that it does not have much redundancy if something unexpected occurs. The larger businesses were regarded to have more redundancy or capacity available, which might be due to their wider range of resources and better access to resources. 
The present resilience of the retail sector was measured by 6 indicators. International retailers seem to demonstrate a high degree of resilience regarding connectedness (indicator 3) as well as reflected and shared learning (indicator 9) compared to national and local actors. Presently the largest retail actors have appropriate connections to their stakeholders in order to minimise risks. In other words, they have plenty of connections to suppliers, several sales channels and customer groups. The experts did not see these connections as a trade-off to maintain flexibility, but as a necessity to minimise risks. However, international retailers demonstrate a low degree of resilience regarding coupling with local natural capital (indicator 8) as well as global autonomy and local interdependency (indicator 10). The retail sector as a whole is, according to experts, poorly associated with building local human capital (indicator 12).

The resilience of consumers was measured by 4 indicators - two of those indicators, (1) socially selforganised and (10) globally autonomous and locally interdependent, came from the general indicator framework. The indicators showed a medium degree of resilience, according to the experts. Two additional indicators measured the awareness of food waste and activities to diminish waste as well as consumer awareness of the environmental and social impacts of food. According to the experts, the low level of awareness of food waste among consumers represents a serious resilience problem in Finland.

\section{The resilience of the Finnish food system in 2050}

The second part of the expert survey used the same indicators to ask questions about the future resilience of the Finnish food system. The results (the mean of the responses) are presented in Table 3.2. Overall, the experts believe the Finnish food system will be clearly more resilient by 2050 compared to today. There were only two indicators that were given a low degree of resilience in the future for certain types of actors, namely indicator 3, appropriately connected, which was a problem for small food industry businesses and indicator 10, globally autonomous and locally interdependent, which was a problem for large food industry businesses and international retailers. In addition, both indicators show a clear negative change for food industry businesses of all sizes from today to 2050 .

[Insert table 3.2 here]

Table 3.2 Future resilience of primary production, food industry and retail according to the expert survey. Primary production is divided into small (S), medium $(M)$, large (L), organic (Org.), plant production $(P P)$ and livestock $(L F)$ farms. Food industry is divided into small $(S)$, medium $(M)$ and large (L) businesses. Retail sector is divided into local (Loc.), national (Nat.) and international (Int.) 
actors. Degree of resilience is illustrated as follows: low (white, mean of responses 0-2.6), medium (light gray, mean of responses 2.7-3.3) and high (dark gray, mean of responses 3.4-5).

\section{Source: the authors}

In primary production, the indicators generally demonstrate a high degree of resilience in the future. Potential future resilience problems in primary production are associated with indicator 5, optimally redundant and indicator 13, reasonably profitable. It appears that the experts believe that large farms will have the best opportunities to build a profitable business. On the other hand, farms may lack reserves and backups for coping with system failure.

The written replies to indicator 2, ecologically self-regulated, emphasised a well-known problem in Finland: the separation between livestock farms and plant production farms, which refers to the fact that manure produced by livestock is not exploited efficiently - often because of logistics. The respondents also stated that there is a much to do before farmers really understand and exploit ecosystem services and local natural resources. However, organic farms were seen as positive exceptions. The relative change from the current situation to 2050 for organic farms appeared to be smaller than for other farm types because they already seem to behave resiliently. The comments also emphasised that it is critical and necessary for future sustainability and resilience to learn and exploit eco-system services and local natural resources sustainably. Some respondents commented that only when the prices of inputs - oil, fertilizers, and pesticides - rise high enough will alternatives be sought and evaluated seriously.

The food industry and retail are expected to build local human capital (indicator 12) in the future, with the exception being international retailers. On the other hand, only local retailers seem to be globally autonomous and locally interdependent (indicator 10). Experts do not foresee international actors in the retail business being globally autonomous because they would still acquire products from global markets. Regarding local actors, the experts foresee more autonomy from the global markets and less concentration.

Indicators 8, coupled with local natural capital, and 9, reflected and shared learning, indicate a high degree of resilience in the future for all actors in the food industry and retail. While the retail sector as a whole as well as large food industry businesses seem to be appropriately connected in the future (indicator 3), this is not true for smaller food industry businesses. In addition, large food industry businesses seem to be more resilient in terms of functional and response diversity (indicator 4). 
The experts on consumer behaviour foresee only positive developments and no negative relative changes from the present to the future. The most significant changes they foresee are the diminishing of food waste and greater consumption awareness.

\section{Implications for climate change adaptation}

The indicator framework of this study measures the general resilience of the Finnish food system, whereas resilience to climate change would require additional specific measures. These specific measures would be very different in agriculture, the food industry, retail and consumption and require sector-specific indicators. Moreover, further disaggregated farm level, factory-level, store-level and even household-level measures would be required because climate change adaptation is notably a local activity in nature and calls for adaptive behaviour and practices at local level. However, general resilience forms a foundation for all kinds of resilience, including climate change adaptation. The tightness of feedbacks, modularity, diversity and self-organising behaviour are all fundamental components of resilience in any kind of system. The critical factors and supply chain phases from the perspective of climate change adaptation are discussed in the following. It should be mentioned, that the experts foresee the mean temperature change being about +2.3 degrees Celsius by 2050 and the impact of climate change on Finnish primary production to be slightly positive. This information can be useful when interpreting their responses concerning the future resilience of the food system.

There are various strengths in the Finnish food system for building resilience to climate change. Organic farms and larger farms are perceived as socially self-organised, which can promote innovations and experimentation to cope with climate change adaptation. Innovations in terms of taking advantage of new circumstances due to discontinuities, is a crucial component of resilience (Beermann 2011). Climate change can involve risks as well as opportunities. In addition, organic farms are currently seen as the most ecologically self-regulated farms. A high degree of ecological self-regulation is seen as promoting short-term adaptation at the farm level in terms of returning to a defined starting point. Moreover, the experts perceive organic farms to be resilient in terms of spatial and temporal heterogeneity. Obviously crop rotation, which is effectively utilised in organic farms, increases their adaptive capacity to climate change as well. Moreover, experts believe organic farms are exposed to low level disturbances more than other farms, helping them to practice self-organising behaviour and increasing their capacity for learning in "safe" circumstances without pushing beyond a critical threshold. 
Organic farms and large food industry businesses are linked to functional and response diversity according to the expert views. Responding to the disruptions caused by climate change and recovering from that by maintaining a continuity of food supply chain operations and objectives is expected to be enabled by accurate diversity. According to the experts, the food industry, especially large- and medium-size businesses, is currently coupled with local natural capital. The experts see the food industry as taking responsibility for its environment and respecting natural resources, including water resources and efficient waste management. Moreover, the Finnish food industry has been actively developing carbon labels for food products in cooperation with research organisations as will be illustrated in chapter 8 .

There are also weaknesses in the Finnish food system that can restrict resilience building. Optimal redundancy is a measure which is not currently associated with the Finnish food system in our expert survey. That is why it is important to reach optimal redundancy, in which efficiency and resilience are in balance. In addition, the retail sector and the food industry, except for small businesses, are not particularly associated with building local human capital. In the future, however, the experts believe that both sectors will improve their performance in those areas. Within the whole food supply chain, the retail sector will probably face the most dramatic changes. Hence, retailers must reconsider their values, purpose and mission in the food supply chain.

Naturally small businesses and local retailers demonstrate a higher degree of resilience in terms of global autonomy and local interdependency compared to large businesses and international actors. According to the experts, this will be the case also in the future - they even see negative developments in terms of appropriate supply chain relationships, global autonomy and local interdependency. Due to concentration and consolidation in the food industry and food retail, large businesses and international retailers will always face the risk of climate change disruptions in their global supplier networks. On the other hand, farmers, large food industry businesses and international retailers are associated with reflected and shared learning. As West (2014) suggests, adaptive management is a continual and iterative learning-by-doing process, which enables collective empowerment and accelerates organisational transformation. In food systems, these transformations are already taking place.

The profitability of farms is and will be a critical cornerstone of the overall resilience of primary production. To ensure food security and adequate supplies of food, the economic, social and environmental dimensions of the vulnerability of the food supply chain must be carefully assessed. 
Climate change introduces potential extra costs for farms that are already struggling with their finance. On the other hand, innovative farms and rural entrepreneurs can explore opportunities related to the changing climate. According to the experts, farmers are associated with honouring legacy, which in turn demonstrates a high degree of trust in the communities of the primary producers. Trust enables horizontal cooperation between farms (supplier cooperation), which is a necessary condition in climate change adaptation.

\section{Conclusion}

The food system experts have very positive views concerning the resilience development of the Finnish food system in the future. The size of the company or farm does not necessarily indicate their degree of overall resilience as there are different kinds of vulnerabilities in small (local) and large (international) businesses. Depending on the resilience indicator, the critical phases of the food supply chain can be found in primary production, in the food industry, in the retail sector or in consumption. Along the whole supply chain, however, food system experts consider organic farms to be the most resilient actor. Maybe other actors in the food supply chain could learn something from the principles of organic farming in their process of resilience building. However, a comparison between the resilient behaviour of different subsystems should be made with caution, as the corresponding measures are partly different. Resilience is a multi-dimensional, multi-faceted and multi-disciplinary phenomenon that is the result of various building blocks. There's no single indicator measuring resilience, although a comprehensive set of resilience indicators are needed.

Resilience indicators can be considered a critical element of the internal side of risk, which includes the conditions of the community or the food system exposed to climate change, and resilience, which closely deals with the capacities for coping and adaptation. This study utilised an indicator framework made for assessing the resilience of agri-ecosystems, but similar frameworks and sets of indicators could be developed for the food industry, the food retail sector and consumption. It is equally important to develop indicator frameworks for measuring resilience specifically for climate change. Measuring the adaptive behaviour and practices of different food supply chain actors, such as supply chain resilience and organisational resilience, with suitable measures could enhance adaptive management within the food supply chain. 


\section{References}

Anderies J M Folke C Walker B and Ostrom E 2013 Aligning Key Concepts for Global Change Policy: Robustness, Resilience, and Sustainability Ecology and Society 18 (2) 8

Beermann M 2011 Linking corporate climate adaptation strategies with resilience thinking Journal of Cleaner Production 19 836-842

Bomford M 2010 Getting fossil fuels off the plate in Heinberg R and Lerch D eds Post Carbon Reader - Managing the 21 st century's sustainability crisis Watershed Media in collaboration with Post Carbon Institute USA 119-127

Cabell J F and Oelofse M 2012 An Indicator Framework for Assessing Agroecosystem Resilience Ecology and Society 17 (1) 18

Carpenter S R Westley F and Turner M G 2005 Surrogates for resilience of social-ecological systems Ecosystems 8 (8) 941-944

Carpenter S R Arrow K J Barrett S Biggs R Brock W A Crepin A Engstrom G Folke C Hughes T P Kautsky N Li C McCarney G Meng K Maler K Polasky S Scheffer M Shogren J Sterner T Vincent J R Walker B Xepapadeas A and de Zeeuw A 2012 General Resilience to Cope with Extreme Events Sustainability 4 (12) 3248-3259

Casti J Ilmola L Rouvinen P and Wilenius M 2011 Extreme events Taloustieto Oy, Helsinki

Davidson J L van Putten I E Leith P Nursey-Bray M Madin E M and Holbrook N J 2013 Toward Operationalizing Resilience Concepts in Australian Marine Sectors Coping with Climate Change Ecology and Society 18(3) 4

Engle N L de Bremond A Malone E L and Moss R H 2013 Towards a resilience indicator framework for making climate-change adaptation decisions Mitigation and Adaptation Strategies for Global Change 1-18 
Ericksen P J 2008a Conceptualizing food systems for global environmental change research Global Environmental Change 18(1) 234-245

Ericksen P J 2008b What is the vulnerability of a food system to global environmental change? Ecology and Society 13(2) 13

Kumar M Srai J Pattinson L and Gregory M 2013 Mapping of the UK food supply chains: capturing trends and structural changes Journal of Advances in Management Research 10 (2) 299-326

Manning L 2013 Corporate and consumer social responsibility in the food supply chain British Food Journal 115(1) 9-29

Meadows D 2008 Thinking in systems - a primer Chelsea Green publishing, USA

Misselhorn A Aggarwal P Ericksen P J Gregory P Horn-Phathanothai L Ingram J and Wiebe K 2012 A vision for attaining food security Current Opinion in Environmental Sustainability 4(1) 7-17

Resilience Alliance 2010 Assessing resilience in social-ecological systems: Workbook for practitioners (Revised version 2.0) (http://www.resalliance.org/index.php/resilience_assessment) Accessed 27 September 2014

Resilience Alliance 2007 Assessing resilience in social-ecological systems: A workbook for scientists (http://www.resalliance.org/index.php/resilience assessment) Accessed 27 September 2014

Rockström J Steffen W Noone K Persson Å Chapin F S Lambin E F Lenton T M Scheffer M Folke C Schellnhuber H J Nykvist B De Wit C A Hughes T Van Der Leeuw S Rodhe H Sörlin S Snyder P K Costanza R Svedin U Falkenmark M Karlberg L Corell R W Fabry V J Hansen J Walker B Liverman D Richardson K Crutzen P and Foley J A 2009 A safe operating space for humanity Nature 461(7263) $472-475$

Sheffi J 2005 Building a resilient supply chain Harvard Business Review 1(8) 1-4

Stigson P 2013 The Resource Nexus: Linkages Between Resource Systems 1-3 
Walker B and Salt D 2006 Resilience thinking: sustaining ecosystems and people in a changing world Island Press, Washington DC

West A 2014 The long hedge Preserving organizational value through climate change adaptation Greenleaf Publishing, Sheffield

Wheeler T and von Braun J 2013 Climate Change Impacts on Global Food Security Science 341(6145) $508-513$

Woods J Williams A Hughes J K Black M and Murphy R 2010 Energy and the food system Philosophical Transactions of the Royal Society B: Biological Sciences, 365 (1554) 2991-3006 


\begin{tabular}{|c|c|c|c|c|c|c|c|c|c|c|c|c|c|c|c|}
\hline \multirow[t]{2}{*}{ Indicator } & \multicolumn{7}{|c|}{ Primary production, i.e. farms } & \multicolumn{4}{|c|}{ Food industry } & \multicolumn{4}{|c|}{ Retail } \\
\hline & $\mathrm{S}$ & MS & $\mathrm{L}$ & Org. & PP & LF & All & $\mathrm{S}$ & MS & $\mathrm{L}$ & All & LOC. & Nat. & Int. & All \\
\hline 1. Socially self-organised & 3.33 & 3.44 & 3.41 & 3.59 & 3.3 & 3.11 & 3.36 & $\mathrm{n} / \mathrm{a}$ & $\mathrm{n} / \mathrm{a}$ & $\mathrm{n} / \mathrm{a}$ & $\mathrm{n} / \mathrm{a}$ & $\mathrm{n} / \mathrm{a}$ & $\mathrm{n} / \mathrm{a}$ & $\mathrm{n} / \mathrm{a}$ & $\mathrm{n} / \mathrm{a}$ \\
\hline $\begin{array}{l}\text { 2. Ecologically self- } \\
\text { regulated }\end{array}$ & 2.79 & 2.57 & 2.43 & 3.61 & 2.5 & 2.79 & 2.78 & $\mathrm{n} / \mathrm{a}$ & $\mathrm{n} / \mathrm{a}$ & $\mathrm{n} / \mathrm{a}$ & $\mathrm{n} / \mathrm{a}$ & $\mathrm{n} / \mathrm{a}$ & $\mathrm{n} / \mathrm{a}$ & $\mathrm{n} / \mathrm{a}$ & $\mathrm{n} / \mathrm{a}$ \\
\hline 3. Appropriately connected & 2.38 & 2.67 & 3.13 & 3.04 & 3.04 & 2.71 & 2.83 & 2.55 & 3.36 & 3.82 & 3.24 & 3.07 & 3.64 & 3.86 & 3.52 \\
\hline $\begin{array}{l}\text { 4. Functional and response } \\
\text { diversity }\end{array}$ & 3.08 & 2.85 & 2.5 & 3.65 & 2.5 & 2.46 & 2.84 & 2.45 & 3.09 & 3.59 & 3.05 & $\mathrm{n} / \mathrm{a}$ & $\mathrm{n} / \mathrm{a}$ & $\mathrm{n} / \mathrm{a}$ & $\mathrm{n} / \mathrm{a}$ \\
\hline 5. Optimally redundant & 2.88 & 2.80 & 2.76 & 2.96 & 2.88 & 2.72 & 2.83 & 2.19 & 2.62 & 2.90 & 2.57 & 2.57 & 2.5 & 2.93 & 2.67 \\
\hline $\begin{array}{l}\text { 6. Spatial and temporal } \\
\text { heterogeneity }\end{array}$ & 2.96 & 2.88 & 3.00 & 4.08 & 2.69 & 3.31 & 3.15 & $\mathrm{n} / \mathrm{a}$ & $\mathrm{n} / \mathrm{a}$ & $\mathrm{n} / \mathrm{a}$ & $\mathrm{n} / \mathrm{a}$ & $\mathrm{n} / \mathrm{a}$ & $\mathrm{n} / \mathrm{a}$ & $\mathrm{n} / \mathrm{a}$ & $\mathrm{n} / \mathrm{a}$ \\
\hline 7. Exposed to disturbances & 3.30 & 3.41 & 3.22 & 3.93 & 3.37 & 3.22 & 3.41 & $\mathrm{n} / \mathrm{a}$ & $\mathrm{n} / \mathrm{a}$ & $\mathrm{n} / \mathrm{a}$ & $\mathrm{n} / \mathrm{a}$ & $\mathrm{n} / \mathrm{a}$ & $\mathrm{n} / \mathrm{a}$ & $\mathrm{n} / \mathrm{a}$ & $\mathrm{n} / \mathrm{a}$ \\
\hline $\begin{array}{l}\text { 8. Coupled with local } \\
\text { natural capital }\end{array}$ & 2.2 & 2.27 & 2.23 & 2.76 & 2.23 & 2.15 & 2.31 & 3.05 & 3.36 & 3.36 & 3.26 & 2.92 & 2.54 & 2.23 & 2.56 \\
\hline $\begin{array}{l}\text { 9. Reflected and shared } \\
\text { learning }\end{array}$ & 3.23 & 3.48 & 4.12 & 4.00 & 3.80 & 3.96 & 3.77 & 2.86 & 3.19 & 3.95 & 3.33 & 2.77 & 3.38 & 3.83 & 3.33 \\
\hline $\begin{array}{l}\text { 10. Globally autonomous } \\
\text { and locally interdependent }\end{array}$ & $\mathrm{n} / \mathrm{a}$ & $\mathrm{n} / \mathrm{a}$ & $\mathrm{n} / \mathrm{a}$ & $\mathrm{n} / \mathrm{a}$ & $\mathrm{n} / \mathrm{a}$ & $\mathrm{n} / \mathrm{a}$ & $\mathrm{n} / \mathrm{a}$ & 3.43 & 3.10 & 2.38 & 2.97 & 3.31 & 2.92 & 1.69 & 2.64 \\
\hline 11. Honours legacy & 3.52 & 3.37 & 3.00 & 3.85 & 3.26 & 3.30 & 3.38 & $\mathrm{n} / \mathrm{a}$ & $\mathrm{n} / \mathrm{a}$ & $\mathrm{n} / \mathrm{a}$ & $\mathrm{n} / \mathrm{a}$ & $\mathrm{n} / \mathrm{a}$ & $\mathrm{n} / \mathrm{a}$ & $\mathrm{n} / \mathrm{a}$ & $\mathrm{n} / \mathrm{a}$ \\
\hline 12. Builds human capital & $\mathrm{n} / \mathrm{a}$ & $\mathrm{n} / \mathrm{a}$ & $\mathrm{n} / \mathrm{a}$ & $\mathrm{n} / \mathrm{a}$ & $\mathrm{n} / \mathrm{a}$ & $\mathrm{n} / \mathrm{a}$ & $\mathrm{n} / \mathrm{a}$ & 3.43 & 3.29 & 2.90 & 3.21 & 2.46 & 2.62 & 2.31 & 2.46 \\
\hline 13. Reasonably profitable & $\mathrm{n} / \mathrm{a}$ & $\mathrm{na}$ & $\mathrm{n} / \mathrm{a}$ & $\mathrm{n} / \mathrm{a}$ & $\mathrm{n} / \mathrm{a}$ & $\mathrm{n} / \mathrm{a}$ & $\mathrm{n} / \mathrm{a}$ & $\mathrm{n} / \mathrm{a}$ & $\mathrm{n} / \mathrm{a}$ & $\mathrm{n} / \mathrm{a}$ & $\mathrm{n} / \mathrm{a}$ & $\mathrm{n} / \mathrm{a}$ & $\mathrm{n} / \mathrm{a}$ & $\mathrm{n} / \mathrm{a}$ & $\mathrm{n} / \mathrm{a}$ \\
\hline In total & 2.97 & 2.97 & 2.98 & 3.55 & 2.96 & 2.97 & & 2.85 & 3.14 & 3.27 & & 2.85 & 2.93 & 2.81 & \\
\hline
\end{tabular}

Source: the authors

Table 3.1 Present status of resilience of primary production, food industry and retail according to the expert survey. Primary production is divided into small (S), medium (M), large (L), organic (Org.), plant production (PP) and livestock (LF) farms. Food industry is divided into small (S), medium (M) and large (L) businesses. Retail sector is divided into local (Loc.), national (Nat.) and international (Int.) actors. Degree of resilience is illustrated as follows: low (white, mean of responses 0-2.6), medium (light gray, mean of responses 2.7-3.3) and high (dark gray, mean of responses 3.4-5). 


\begin{tabular}{|c|c|c|c|c|c|c|c|c|c|c|c|c|c|c|c|}
\hline \multirow[t]{2}{*}{ Indicator } & \multicolumn{7}{|c|}{ Primary production, i.e. farms } & \multicolumn{4}{|c|}{ Food industry } & \multicolumn{4}{|c|}{ Retail } \\
\hline & $\mathrm{S}$ & MS & $\mathrm{L}$ & Org. & PP & $\mathrm{LF}$ & All & $\mathrm{S}$ & MS & $\mathrm{L}$ & All & LOC. & Nat. & Int. & All \\
\hline 1. Socially self-organised & 3.74 & 3.63 & 3.52 & 3.89 & 3.59 & 3.44 & 3.64 & $\mathrm{n} / \mathrm{a}$ & $\mathrm{n} / \mathrm{a}$ & $\mathrm{n} / \mathrm{a}$ & $\mathrm{n} / \mathrm{a}$ & $\mathrm{n} / \mathrm{a}$ & $\mathrm{n} / \mathrm{a}$ & $\mathrm{n} / \mathrm{a}$ & $\mathrm{n} / \mathrm{a}$ \\
\hline $\begin{array}{l}\text { 2. Ecologically self- } \\
\text { regulated }\end{array}$ & 3.59 & 3.67 & 3.7 & 4.00 & 3.63 & 3.96 & 3.76 & $\mathrm{n} / \mathrm{a}$ & $\mathrm{n} / \mathrm{a}$ & $\mathrm{n} / \mathrm{a}$ & $\mathrm{n} / \mathrm{a}$ & $\mathrm{n} / \mathrm{a}$ & $\mathrm{n} / \mathrm{a}$ & $\mathrm{n} / \mathrm{a}$ & $\mathrm{n} / \mathrm{a}$ \\
\hline 3. Appropriately connected & 3.56 & 3.79 & 3.88 & 3.96 & 3.92 & 3.72 & 3.81 & 2.45 & 3.09 & 3.59 & 3.05 & 3.85 & 4.15 & 3.85 & 3.95 \\
\hline $\begin{array}{l}\text { 4. Functional and response } \\
\text { diversity }\end{array}$ & 3.73 & 3.73 & 3.54 & 3.92 & 3.65 & 3.35 & 3.65 & 3.33 & 3.71 & 4.05 & 3.70 & $\mathrm{n} / \mathrm{a}$ & $\mathrm{n} / \mathrm{a}$ & $\mathrm{n} / \mathrm{a}$ & $\mathrm{n} / \mathrm{a}$ \\
\hline 5. Optimally redundant & 2.96 & 3.08 & 3.00 & 3.20 & 3.16 & 3.00 & 3.07 & 2.81 & 2.90 & 3.00 & 2.90 & 2.75 & 2.85 & 3.15 & 2.92 \\
\hline $\begin{array}{l}\text { 6. Spatial and temporal } \\
\text { heterogeneity }\end{array}$ & 3.50 & 3.69 & 3.96 & 4.24 & 3.68 & 3.88 & 3.83 & $\mathrm{n} / \mathrm{a}$ & $\mathrm{n} / \mathrm{a}$ & $\mathrm{n} / \mathrm{a}$ & $\mathrm{n} / \mathrm{a}$ & $\mathrm{n} / \mathrm{a}$ & $\mathrm{n} / \mathrm{a}$ & $\mathrm{n} / \mathrm{a}$ & $\mathrm{n} / \mathrm{a}$ \\
\hline 7. Exposed to disturbances & 3.38 & 3.35 & 3.31 & 3.58 & 3.38 & 3.38 & 3.40 & $\mathrm{n} / \mathrm{a}$ & $\mathrm{n} / \mathrm{a}$ & $\mathrm{n} / \mathrm{a}$ & $\mathrm{n} / \mathrm{a}$ & $\mathrm{n} / \mathrm{a}$ & $\mathrm{n} / \mathrm{a}$ & $\mathrm{n} / \mathrm{a}$ & $\mathrm{n} / \mathrm{a}$ \\
\hline $\begin{array}{l}\text { 8. Coupled with local } \\
\text { natural capital }\end{array}$ & 3.96 & 4.23 & 4.24 & 4.38 & 4.19 & 4.23 & 4.21 & 4.00 & 4.14 & 4.05 & 4.06 & 4.38 & 4.08 & 3.69 & 4.05 \\
\hline $\begin{array}{l}\text { 9. Reflected and shared } \\
\text { learning }\end{array}$ & 4.16 & 4.24 & 4.40 & 4.36 & 4.32 & 4.36 & 4.31 & 3.81 & 3.95 & 4.10 & 3.95 & 4.00 & 4.08 & 4.25 & 4.11 \\
\hline $\begin{array}{l}\text { 10. Globally autonomous } \\
\text { and locally interdependent }\end{array}$ & 3.42 & 3.35 & 3.31 & 3.54 & 3.31 & 3.58 & 3.42 & 3.10 & 2.76 & 2.14 & 2.67 & 3.85 & 3.33 & 2.15 & 3.11 \\
\hline 11. Honours legacy & 3.7 & 3.56 & 3.37 & 3.78 & 3.59 & 3.59 & 3.60 & $\mathrm{n} / \mathrm{a}$ & $\mathrm{n} / \mathrm{a}$ & $\mathrm{n} / \mathrm{a}$ & $\mathrm{n} / \mathrm{a}$ & $\mathrm{n} / \mathrm{a}$ & $\mathrm{n} / \mathrm{a}$ & $\mathrm{n} / \mathrm{a}$ & $\mathrm{n} / \mathrm{a}$ \\
\hline 12. Builds human capital & $\mathrm{n} / \mathrm{a}$ & $\mathrm{n} / \mathrm{a}$ & $\mathrm{n} / \mathrm{a}$ & $\mathrm{n} / \mathrm{a}$ & $\mathrm{n} / \mathrm{a}$ & $\mathrm{n} / \mathrm{a}$ & $\mathrm{n} / \mathrm{a}$ & 3.9 & 3.85 & 3.67 & 3.81 & 4.00 & 3.62 & 3.31 & 3.64 \\
\hline 13. Reasonably profitable & 2.62 & 2.85 & 3.42 & 3.15 & 3.12 & 3.31 & 3.08 & $\mathrm{n} / \mathrm{a}$ & $\mathrm{n} / \mathrm{a}$ & $\mathrm{n} / \mathrm{a}$ & $\mathrm{n} / \mathrm{a}$ & $\mathrm{n} / \mathrm{a}$ & $\mathrm{n} / \mathrm{a}$ & $\mathrm{n} / \mathrm{a}$ & $\mathrm{n} / \mathrm{a}$ \\
\hline In total & 3.53 & 3.6 & 3.64 & 3.83 & 3.63 & 3.65 & & 3.34 & 3.49 & 3.51 & & 3.81 & 3.69 & 3.4 & \\
\hline
\end{tabular}

Source: the authors

Table 3.2 Future resilience of primary production, food industry and retail according to the expert survey. Primary production is divided into small (S), medium (M), large (L), organic (Org.), plant production (PP) and livestock (LF) farms. Food industry is divided into small (S), medium (M) and large (L) businesses. Retail sector is divided into local (Loc.), national (Nat.) and international (Int.) actors. Degree of resilience is illustrated as follows: low (white, mean of responses 0-2.6), medium (light gray, mean of responses 2.7-3.3) and high (dark gray, mean of responses 3.4-5). 